\title{
Differential proteomics in contrasting cowpea genotypes submitted to different water regimes
}

\author{
E.N. Lima ${ }^{1}$, M.L. dos S. Silva ${ }^{1}$,C.E.B. de Abreu ${ }^{1}$, R.O. Mesquita ${ }^{1}$, \\ M.D.P. Lobo ${ }^{2}$, A.C. de O. Monteiro-Moreira ${ }^{2}$, E. Gomes-Filho ${ }^{1}$ and \\ C.H.C. de M. Bertini ${ }^{1}$ \\ ${ }^{1}$ Departamento de Ciência Vegetal, Bioquímica e Biologia Molecular, \\ Universidade Federal do Ceará, Fortaleza, Brasil \\ ${ }^{2}$ Centro de Ciências da Saúde, Universidade de Fortaleza, Fortaleza, CE, \\ Brasil \\ Corresponding author: E.N. Lima \\ E-mail: evelinenlima@gmail.com
}

Genet. Mol. Res. 18 (4): gmr18396

Received June 13, 2019

Accepted September 24, 2019

Published November 30, 2019

DOI http://dx.doi.org/10.4238/gmr18396

\begin{abstract}
Cowpea (Vigna unguiculata) is of great importance for human consumption due to its high nutritional value. The crop is grown in tropical and subtropical regions of the world; however, grain productivity is severely affected by water restriction imposed by long periods of drought in semiarid regions. We compared two contrasting cowpea genotypes for drought tolerance through proteomic analyses by identifying differentially expressed proteins responsive to water deficit and associating them with physiological responses. Water stress-tolerant (Pingo de Ouro 1,2) and sensitive (Santo Inácio) cowpea genotypes were submitted to moderate $(\Psi \mathrm{pd}=-1.0 \mathrm{MPa})$ and severe $(\Psi \mathrm{pd}=-1.5 \mathrm{MPa})$ water deficit conditions, re-irrigation after severe water deficit, and a full irrigation regime as a control. Physiological responses and expressed proteins in response to water stress were assessed. Pingo de Ouro 1,2 showed drought tolerance by delaying dehydration, being efficient in stomatal control, increasing photosynthesis and reducing transpiration rates. Based on proteomic analysis, 108 differentially expressed proteins were identified that may be associated with drought response in both tolerant and sensitive genotypes. Drought stress-response peptides, including glutamine synthetase, CPN60-2 chaperonin, malate dehydrogenase, heat-shock proteins, and rubisco were expressed differentially in both genotypes. The changes in the proteome in cowpea
\end{abstract}


leaves in response to drought can help us understand the mechanisms and specific metabolic pathways involved in drought tolerant and drought sensitive cowpea genotypes.

Key words: Vigna unguiculata; Two-dimensional electrophoresis; Mass spectrometry; Proteins; Photosynthesis

\section{INTRODUCTION}

Cowpea (Vigna unguiculata) is cultivated mainly in the North and Northeast regions of Brazil (Nascimento et al., 2011). The grains has high nutritional value and constitutes a main food mainly for poor people in these regions, where cowpeas are relatively more affordable than other options (Silva et al., 2010). However, water deficit condition in the Northeast is a limiting adverse condition for crop production, especially in small farms (Donohue et al., 2013).

Considering the importance of cowpea for the North and Northeast regions of Brazil, it is important to study the performance of cultivars developed for rainfed cultivation, faced with the imposed water limitations in these regions during the year. Many adaptive mechanisms for drought tolerance have been described in cowpea, which proves its tolerance to drought and heat (Nascimento et al., 2004; Santos et al., 2010; Nascimento et al., 2011; Bastos et al., 2012; Sousa et al., 2015; Rivas et al., 2016; Rodrigues et al., 2016). Mechanisms affecting almost all crop growth stages and water stress responses have a genetic component (Muchero et al., 2008), which makes cowpea an interesting model to investigate the adaptation basis to drought (Goufo et al., 2017). Thus, it is important to understand the physiological and genetic changes in plants related to drought tolerance or resistance, since both tolerant and resistant plants develop drought recovery responses for progressive acclimatization to stress (Goufo et al., 2017).

Physiological mechanisms are triggered and adapted to allow the maintenance of water in the soil, aiming to save water for future periods of drought (Taiz and Zeiger, 2010). In bean plants, water deficit decreases stomatal conductance and increases diffusive resistance to water vapor through stomatal closure which reduces transpiration and, consequently, $\mathrm{CO}_{2}$ supply for photosynthesis (Oliveira et al., 2005). These mechanisms together with molecular genetics have been used to identify important genes in determining drought resistance/tolerance characteristics. Studies of such genes have grown increasingly important for biotechnology, given the water scarcity that has been progressively worsening globally.

Stress-induced genes play a role not only in producing important metabolism proteins, as well as in regulating genes involved in signal transduction (Kalefetoğlu and Ekmekçi, 2005), and proteins that probably work in the stress response. Studies on the proteomics of water stress have been conducted in different crop species, such as common bean (Zadražnik et al., 2013), wheat (Peng et al., 2009), rice (Ke et al., 2009), and maize (Alvarez et al., 2008). These studies are important because they make possible to better understand the complex water stress response mechanisms. In addition, identifying peptides and genes may be useful for the development of new varieties less susceptible to drought.

Pingo de Ouro 1,2 and Santo Inácio genotypes are considered drought tolerant and sensitive, respectively (Nascimento et al., 2011; Rivas et al., 2016; Rodrigues et al., 2016). 
However, protein dynamics of drought tolerance in these genotypes has not yet been investigated. Thus, this study aimed to identify the differentially expressed proteins (increase or decrease in the expression in terms of relative abundance) in these contrasting cowpea genotypes by submitting them to different water deficit regimes.

\section{MATERIAL AND METHODS}

The experiment was conducted from July to August 2015 under greenhouse condition, at the Federal University of Ceará, Fortaleza, Brazil. Inside the greenhouse was recorded $35 \pm 5{ }^{\circ} \mathrm{C}$ temperature and $70 \pm 20 \%$ relative humidity. Two cowpea genotypes $(V$. unguiculata), tolerant (Pingo de Ouro 1,2) and sensitive (Santo Inácio) to water deficit (Nascimento et al., 2011; Rifas et al., 2016), were cultivated using seeds provided by Embrapa Mid-North (Teresina, Piauí, Brazil) and the Germplasm Bank of the Federal University of Ceará, respectively.

Three seeds from each genotype were sown in pots with $11 \mathrm{~L}$ capacity, filed with a substrate composed by sand, earthworm humus and vermiculite (6:3:1 volume), irrigated daily. Ten days after sowing, thinning was performed keeping one seedling per pot. When reached the pre-flowering stage (V4 Stage), plants were submitted to four irrigation regimes: (1) full irrigation (control); (2) moderate water deficit condition [leaf predawn water potential $(\Psi \mathrm{pd})=-1.0 \pm 0.1 \mathrm{MPa}$; ; $(3)$ severe water deficit condition $(\Psi \mathrm{pd}=-1.5 \pm$ $0.1 \mathrm{MPa}$ ); and (4) plant rewatering regime. In the fourth treatment, after submitted to severe water deficit condition, plants were re-irrigated and evaluated after four days after to assess the recovery responses to drought.

Then, gas exchange indexes $\left[\left(\mathrm{CO}_{2}\right.\right.$ net assimilation rate $(\mathrm{A})$, stomatal conductance to water vapor $\left(\mathrm{g}_{\mathrm{s}}\right)$, transpiration rate $(\mathrm{E})$, and internal $\mathrm{CO}_{2}$ concentration $(\mathrm{Ci})$ ] were assessed by using an infrared gas analyzer (IRGA, LI-6400XT, LI-COR Biosciences Inc., Lincoln, Nebraska, USA) and free proline content in leaves were evaluated according to Bates et al., (1973).

The experimental design was completely randomized (DIC) in a $4 \times 2$ factorial arrangement, with five replicates, being water regime as the first factor and genotypes as the second one. Data were submitted to analysis of variance by the $\mathrm{F}$ test $(\mathrm{P}<0.05)$ and mean values were grouped by Tukey's test $(\mathrm{P}<0.05)$. Statistical analyses were performed using SISVAR 5.0 software, and graphs were elaborated using SigmaPlot 11.0 software.

\section{Proteomic analysis}

Leaves (second and third fully-expanded leaves from the apex) from plants of each treatment were collected, then rolled in aluminized paper envelopes, frozen with liquid nitrogen, then stored at $-80^{\circ} \mathrm{C}$ for proteomic analysis. Differential proteomic analysis between cowpea genotypes was carried out in leaves collected from the plant under the moderate $(-1.0 \mathrm{MPa})$ and severe $(-1.5 \mathrm{MPa})$ water deficit regimes.

Total protein extraction was carried out in five biological replications. The leaves were macerated in liquid nitrogen, and the extraction performed based on the method described by Mesquita et al., (2012). Protein concentration was determined according to Bradford (1976). 


\section{Two-dimensional electrophoresis (2D-PAGE) and spot revelation}

The protein samples were solubilized in rehydration solution [7M urea, $2 \mathrm{M}$ thiourea, 65 $\mathrm{mM}$ DTT, 2\% (w/v) CHAPS, $2 \%(\mathrm{v} / \mathrm{v})$ IPG buffer and $0.02 \%$ bromophenol blue] for $16 \mathrm{~h}$ in rehydration vats (Reswelling Tray II, Pharmacia Biotech). Then, the rehydrated strips were submitted to isoelectric separation using the following schedule: $200 \mathrm{~V}$ (Stp) for $60 \mathrm{~min} ; 500 \mathrm{~V}$ (Stp) for $500 \mathrm{Vxh} ; 1000 \mathrm{~V}$ (Grd) for $800 \mathrm{Vxh} ; 8000 \mathrm{~V}$ (Stp) for $11300 \mathrm{Vxh} ; 8000 \mathrm{~V}$ (Grd) for $6500 \mathrm{Vxh} ; 6300 \mathrm{~V}$ (Stp) for 8h in the Ettan IPGphor 3 system (GE Healthcare).

After isoelectric focusing of the strips, two equilibration steps were performed in order to reduce and alkylate the proteins. First, the strips were immersed in an equilibrium solution [1.5 M Tris-HCl, $\mathrm{pH} 8.8,87 \%$ (v/v) glycerol, $6 \mathrm{M}$ urea, 2\% SDS (m/v) and bromophenol blue] containing $1 \%(\mathrm{w} / \mathrm{v})$ DTT under slow stirring for $20 \mathrm{~min}$; and then, the strips were immersed in an equilibrium solution containing $2.5 \%(\mathrm{w} / \mathrm{v})$ iodoacetamide, again under slow stirring for 20 $\min$.

The two dimension (SDS-PAGE) was carried out on a homogeneous vertical gel (14x14 $\mathrm{cm}$ ), in tahe SE 600 Ruby vertical electrophoresis unit (GE-Healthcare) by fixing the focused strips on the $12.5 \%$ polyacrylamide gel using a $0.5 \%(\mathrm{w} / \mathrm{v})$ agarose and $0.002 \%(\mathrm{w} / \mathrm{v})$ bromophenol blue solution to attach the strips to the top of the gel. Protein separation, according to molecular weight, was done using an EPS 3501 XL power supply (Neuhoff et al., 1988). The gels were fixed in acetic acid solution $10 \%(\mathrm{v} / \mathrm{v})$ and ethanol $40 \%(\mathrm{v} / \mathrm{v})$ for $24 \mathrm{~h}$, and then stained with colloidal staining solution for $48 \mathrm{~h}$.

Gels were scanned using LabScan v.5.0 software (GE-Healthcare) on an ImageScanner (Amersham Biosciences); the images were obtained in .mel format and analyzed with the ImageMaster 2D Platinum 7.0 software (GE-Healthcare). Through this program, the isoelectric points and the molecular weights of each protein (spot) were estimated.

Once the spots were detected, the gels were combined and merged into a master gel containing the spots found on all analyzed gels. A comparison of the master gel with the other gels from the treatments allowed the differentially expressed spots to be visualized.

The comparison was made between plant gels under different water regimes comparing the differences between the contrasting genotypes for drought and comparison between irrigated plants and under water deficits in the tolerant and sensitive genotypes, considering three biological replicates for each treatment. Spots that presented an overlap variation of measurements over 1.5 times and significantly different ( $F$ test at $p<0.05$ ) were considered differentially expressed.

\section{Spot processing, mass spectrometry, and protein identification}

The spots were manually removed from the stained gels, then bleached and digested with trypsin (Promega, Madison, WI, USA), as described by Shevchenko et al., (2006). After the samples were treated, they were transferred to clean microtubes, dried in a vacuum centrifuge (SpeedVac SVC 100H, Svant, USA), and then stored in a freezer at $-80^{\circ} \mathrm{C}$ for further analysis by mass spectrometry.

The peptides from the tryptic digestion were analyzed by sequential mass spectrometry with electrospray ionization, coupled to liquid chromatography (Nano-high performance, UPLC), which was coupled to a high-resolution hybrid mass spectrometer (Q-TOF), with two mass analyzers, one quadruple (Q) and a flight time analyzer (TOF-Time-of-flight) (Waters Corp, Milford, MA, USA). The resulting mass spectra (.raw) were collected and processed using the ProteinLynx Global Server 2 software (Walters Co.) and later converted to micro mass (.pkl) 
files. These files were loaded into the Mascot v.2.2 software (Matrix Science) for confirmation of protein identity in sequences research against the NCBI database (National Centre for Biotechnology Information).

The parameters used for protein search were peptides with up to two lost cleavage sites, +1.2 Da error for peptide identification; as variable modifications were chosen carbamidomethylation of the cysteine residues, and oxidation of methionine residues. For the identified proteins, the Uniprot software (www.uniprot.org/) was used to characterize the metabolic pathways and biological functions that the proteins are involved in.

\section{Physiological and proteome analysis}

Data obtained using two-dimensional electrophoresis (2-DE) along with mass spectrometry (MS) and the results of the physiological responses were used to investigate differences in foliar proteome between the two cowpea genotypes.

\section{RESULTS}

Physiological and biochemical response of contrasting cowpea genotypes to different water regimes

Santo Inácio plants reached $\Psi$ pd around -1.0 and -1.5 MPa after 10 days from irrigation suspension, while Pingo de Ouro 1,2 needed two more days to reach the same $\Psi$ pd levels (Figure 1). These results show that Pingo de Ouro 1,2 saves more water than Santo Inácio. However, all physiological parameters were not significantly different between genotypes under the full irrigation regime (Figure 1). Under water deficit condition the photosynthetic rate decreased in both genotypes but recovered when plants were re-irrigated.

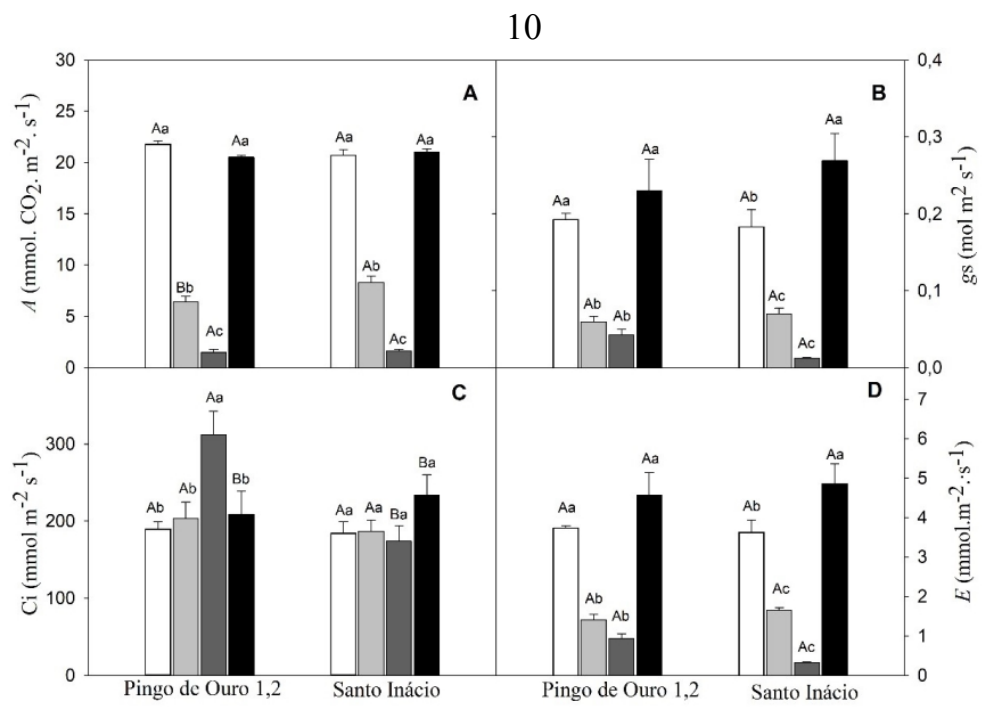

Figure 1. Gas exchange indexes $\left[\mathrm{CO}_{2}\right.$ net assimilation rate $(A)$, stomatal conductance to water vapor $\left(g_{s}\right)$, transpiration rate $(E)$ and internal $\mathrm{CO}_{2}$ concentration $(C i)$ ] in Santo Inácio and Pingo de Ouro 1,2 cowpea genotypes. Irrigation regimes: $(\square)$ full irrigation, ( $\square$ ) moderate water deficit condition, ( $\square$ ) severe water deficit condition, and ( $\square)$ re-irrigated regime. Each bar represents mean \pm standard deviation $(n=5$, where $n$ represents the number of plants). 
Santo Inácio showed a variation in $g_{s}\left(0.06 \mathrm{~mol} \mathrm{~m}^{2} \mathrm{~s}^{-1}\right.$ and $\left.0.01 \mathrm{~mol} \mathrm{~m}^{2} \mathrm{~s}^{-1}\right)$ under moderate and severe water deficit conditions compared to control, which indicates closure of stomata in response to water deficit. In contrast, Pingo de Ouro 1,2 showed higher $g_{s}$ which allows photosynthesis even under low water availability.

Under severe water deficit, $\mathrm{Ci}$ increased in the tolerant genotype while decreased in the sensitive (Figure 1C). Also, both genotypes reduced E, but strongly reduced in Santo Inácio under severe water deficit (Figure 1D).

Water stress increased proline content in leaves of both genotypes and the accumulation of these osmolytes was even greater under severe stress (Figure 2). Although, Santo Inácio accumulated more proline than Pingo de Ouro 1,2 under full irrigation and moderate water stress.

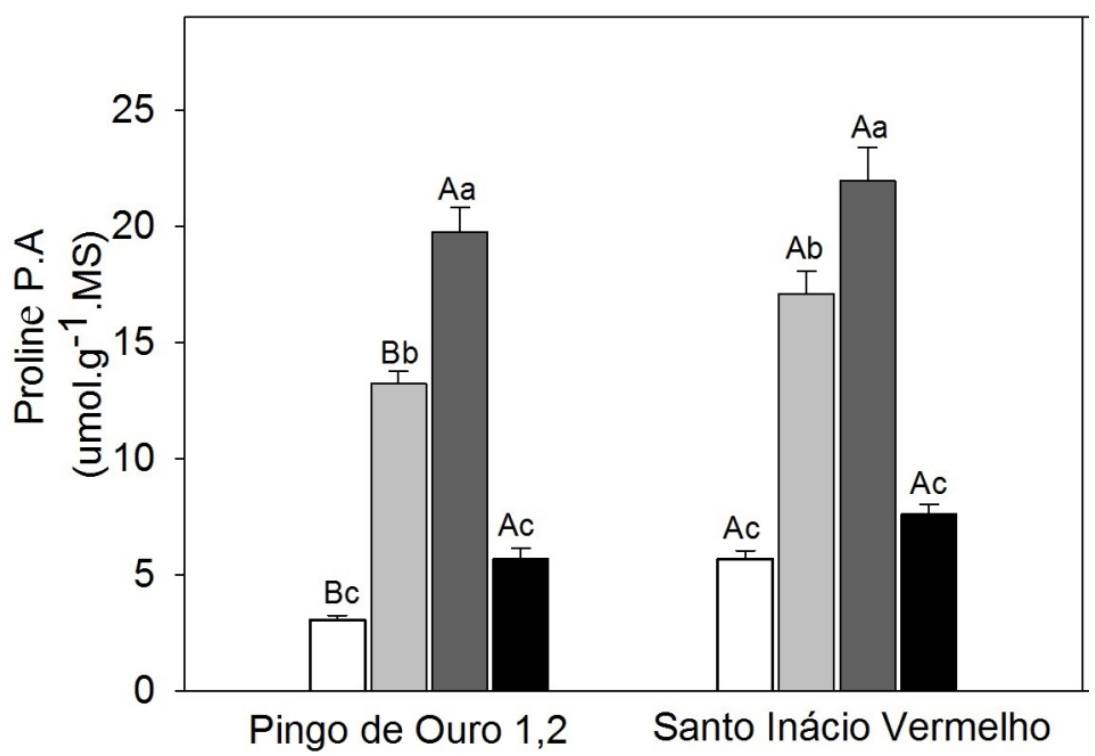

Figure 2. Proline content in cowpea leaves. Irrigation regimes: ( $\square$ ) full irrigation, ( $\square$ ) moderate water deficit condition, ( $\square)$ severe water deficit condition, and ( $\square)$ re-irrigated regime. Each bar represents mean \pm standard deviation ( $n=5$, where $n$ represents the number of plants).

\section{2-DE protein analysis of the cowpea genotype}

Analyzing the images of two-dimensional leaf gels of both cowpea genotypes, a total of 120 differentially expressed spots were detected. From this total, 108 were identified by MS / MS. Figure 3 shows spots that presented differential abundance in the tolerant and sensitive genotypes under the control irrigation regime, and that was removed for analysis by MS and for detection by MS/MS. Such a comparison is important to identify constitutive changes in protein expression that may be associated with genetic differences rather than drought tolerance mechanisms.

The identified proteins are presented in Supplementary 1 according to similarity analysis with other protein sequences already deposited at NCBI (Database for Bioinformatics Research). The table includes spot number, database accession number, 
protein identity, reference organism, values of isoelectric point, and molecular mass (experimental and theoretical), score, sequence coverage, and biological process. Proteins with expression differentiated in the studied genotypes are involved in different important processes such as protein metabolism and wrapping, photosynthesis, respiration, and energy metabolism.

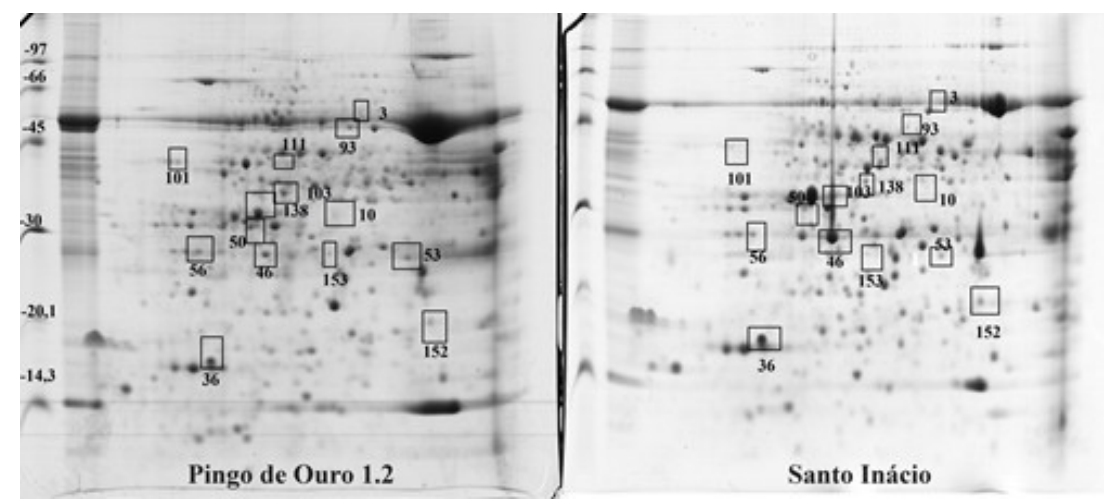

Figure 3. Proteins with differential expression in leaves of drought-tolerant (Pingo de Ouro 1.2) and droughtsensitive (Santo Inácio) cowpea genotypes under full irrigation regime.

Relevant proteins relating to protein metabolism were not found in both cowpea genotypes under full irrigation and moderate water deficit condition. However, under severe water deficit, proteins involved in protein syntheses such as glutamine synthetase (spot 65), cysteine synthase (spot 55), PHAVU_009G224900g (spot 23), and chaperonin CPN60-2, mitochondrial (spot 85) were found. These proteins play important roles in antioxidant stress defense metabolism. Thus, improvement in antioxidant defense in plants may, therefore, increase genotype tolerance to different stress conditions. Spots 65 and 85 increased abundantly in the tolerant genotype and may be relevant in molecular mechanisms to confer tolerance in Pingo de Ouro 1,2.

Also, under severe water stress, the "eukaryotic translation initiation factor 5A-2" (spot 19) protein was expressed and more pronounced in the sensitive than in the tolerant cowpea genotype. This protein is involved in senescence and drought tolerance mechanisms (Feng et al., 2007) and indicates that in the sensitive genotype, drought was more impacting in the protein accumulation since it was more strongly repressed.

Under full irrigation, photosynthesis-related proteins [chlorophyll a-b binding protein (spot 56) and protein 5 containing PsbP domains, chloroplast, partial (spot 153)] were found. The expression of these proteins increased in the tolerant genotype compared to the sensitive. It may explain why tolerant genotype maintains photosynthesis enough to maintain plant growth even under drought conditions. In contrast, oxygen enhancer 1, chloroplast (spot 138) and putative rubisco activase proteins, partial (spot 152), reduced expression when comparing tolerant and sensitive genotypes, indicating drought conditions increase such proteins in sensitive genotype, while decrease in tolerant.

On the other hand, photosynthesis-related proteins expressed under severe water stress were fructose bisphosphate aldolase, 1 cytoplasmic isoenzyme (spot 59), and fructose bisphosphate aldolase, similar to 1 cytoplasmic isoenzyme (spot 64), being that spot 59 increased in tolerant genotype and spot 64 increased in sensitive genotype. These results 
suggest that spot 59 performed an essential role at the photosynthesis maintaining while spot 64 was inhibited in the tolerant genotype.

The proteins relevant to respiration and energy metabolism processes were Pyruvate dehydrogenase E1 component subunit beta (spot 111). This protein participates in the first component of the enzymatic complex responsible for the respiration process and its abundance decreased in the tolerant genotype. The LR48_Vigan03g317700 protein (spot 3) related to catalytic activities also decreased in the tolerant genotype.

Proteins involved with $\mathrm{CO}_{2}$ fixation were also identified. The large subunit of Rubisco (spot 115), which catalyzes the first and main reaction of the Calvin cycle, and fructose-1,6-bisphosphatase, which catalyzes the conversion of fructose-1,6-bisphosphate into fructose-6-phosphate, were enzymes with increased expression in the tolerant genotype compared to the sensitive one. These results are according to a significant difference in net photosynthesis when genotypes were submitted to water deficit compared to full irrigation, and a significant difference between genotypes under moderate stress conditions.

Differential proteome of water-deficit responsive proteins in the tolerant cowpea genotype (Pingo de Ouro 1,2)

At Venn diagram are presented the number of responsive proteins identified in leaves of the tolerant genotype (Pingo de Ouro 1,2) under water deficit and full irrigation conditions (Figure 4). Under moderate water stress, 22 proteins with differential abundance compared to control were identified, from which 11 reduced while the other 11 increased in response to stress. Whilst, under severe water stress, 16 proteins were observed, from which four reduced expression while 12 increased due to stress (Figure 4).

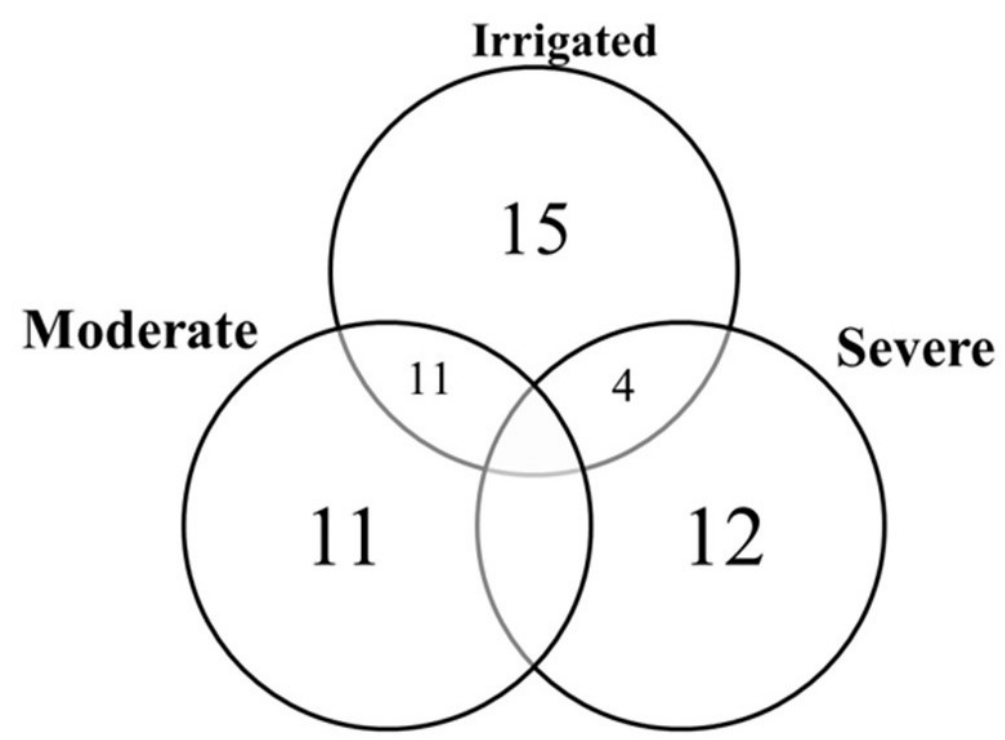

Figure 4. Venn diagram of differentially expressed proteins in leaves of Pingo de Ouro 1,2 cowpea under water deficit conditions compared to full irrigation.

Under moderate water stress conditions, different groups of responsive proteins were found: photosynthesis, protein metabolism, RNA metabolism, respiration and energy 
metabolism, carbohydrate metabolism, and signaling, with predominant expression of photosynthesis-related proteins $(27 \%)$. In turn, under severe deficit were found proteins related to protein metabolism, photosynthesis, nitrogen metabolism, respiration, and energy metabolism, carbon metabolism, and signaling. However, differential expression of proteins related to protein metabolism, photosynthesis, respiration, and energy metabolism was equivalent in number.

At spots 20, 56, 70, 105, 107 and 131 (Figure 5) are the proteins related to photosynthesis, being those in 70, 107 and 13 increased expression in moderate water deficit. GLYMA_18G244900 (spot 70), VIGAN_05238000 (spot 107), and PREDICTED: 2-methylene-furan-3-one reductase (spot 131) proteins participate in photorespiration process, which is a light-dependent phenomenon of $\mathrm{O}_{2}$ absorption and $\mathrm{CO}_{2}$ evolution during photosynthesis in plants. Increased synthesis of these proteins indicates increased photorespiration that negatively affects the photosynthesis rate.

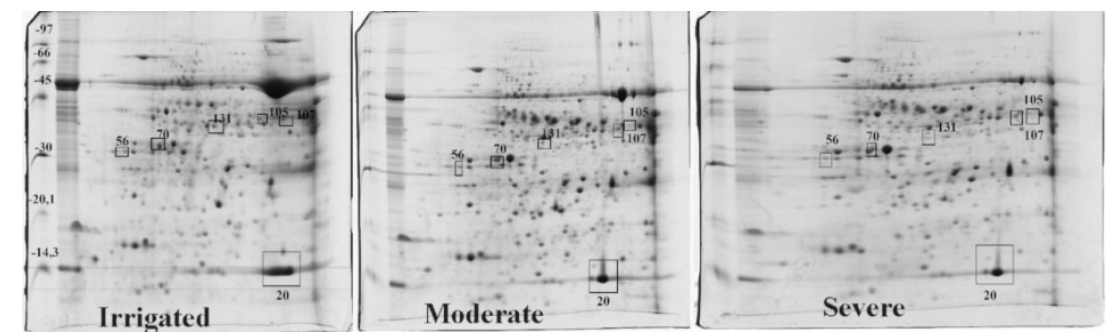

Figure 5. Two-dimensional gels of proteins extracted with Coomassie from leaves of Pingo de Ouro 1,2 cowpea grown under full irrigation and moderate and severe water stress conditions.

Spot 99 (Malate dehydrogenase) revealed an alteration in both moderate and severe water deficit, with increased expression by 2.88 and 4.03 -fold respectively.

So, the more this genotype is exposed to water stress, the more this protein is expressed. Having its expression induced by drought, this protein is important in stomatal closure regulation to avoid water loss.

Under severe water stress condition predominated proteins related to protein metabolism: proteasome subunit alpha type 6 (spot 6), LR48_Vigan01g229200 (spot 50), and PHAVU_011G082600g (spot 98), which is related to proteolysis, nucleic acid synthesis, and protein folding, respectively. They had increased expression and just were found in the tolerant genotype.

Photosynthesis-related proteins at spots 20,86 , and 138 predominated under severe water deficit compared to control. The small subunit of Rubisco (Ribulose-1,5-bisphosphate carboxylase/oxygenase), an enzyme that acts on carbon fixation in the Calvin-Benson Cycle), partial (spot 20), was also expressed under the moderate water deficit, but its expression decreased with increasing water stress intensity. Similarly, a protein related to respiration and energy metabolism at spot 94 (ATP synthase CF1 beta-chloroplast subunit) decreased expression when submitted to severe water deficit. The large subunit of Rubisco, however, reduced expression in both moderate (3.94-fold) and severe (3.00-fold) stress compared to control (Figure 6). The expression of this enzyme decreased with increasing stress intensity. This can be an important mechanism for maintaining enough photosynthesis levels to maintain plant growth. 


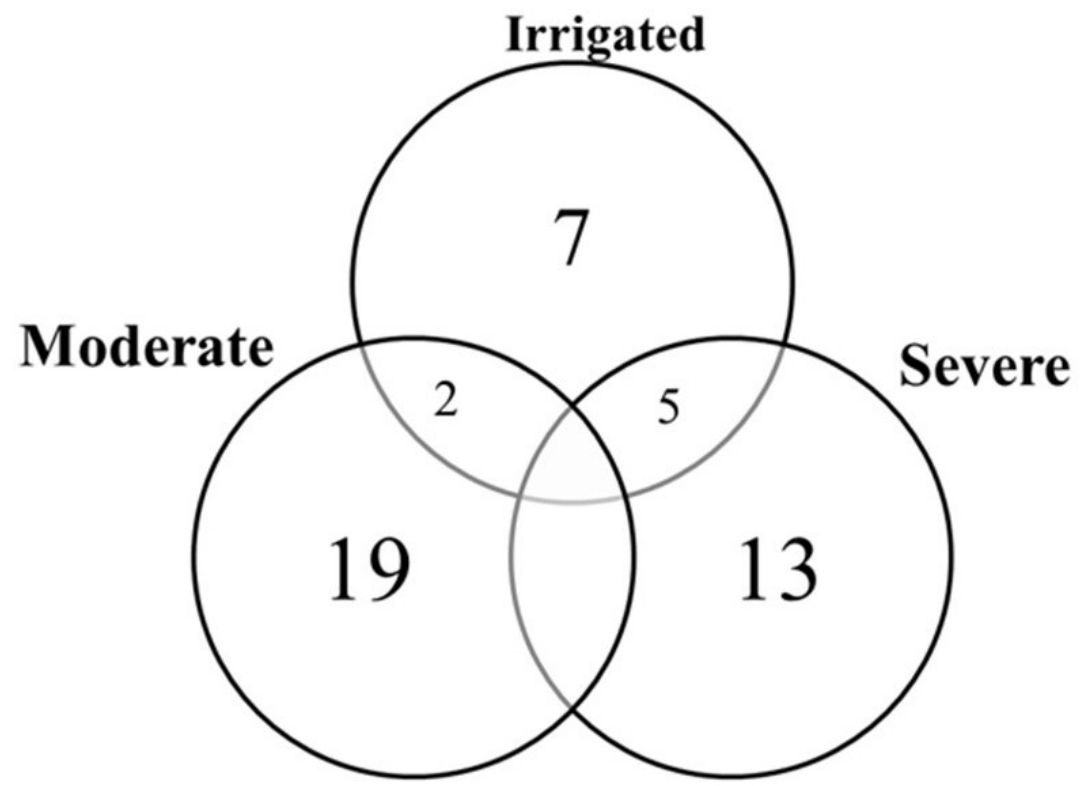

Figure 6. Detail of spot 115 from cowpea leaves differentially expressed under water deficit. Graphs show values for mean volume percent + standard deviation under each water deficit condition. Figure 6A: full irrigation $\mathrm{x}$ moderate water stress; Figure 6B: full irrigation x severe water stress.

Differential proteome of water-deficit responsive proteins in the sensitive cowpea genotype (Santo Inácio)

In Santo Inácio, it was found a higher number (31) of responsive proteins under moderate water stress, higher than in Pingo de Ouro 1,2; 21 different proteins and 10 possible isoforms or modifications of the same protein, which was represented by more than one spot in the same gel. From the total, two with reduced expression while the other 19 with increased expression. In turn, under severe water stress, 19 proteins were found, from which 18 were classified as differential proteins. From these 18, five were reduced and 13 increased (Figure 7).

Under moderate water deficit, different functional groups of proteins were identified: photosynthesis, stress, amino-acid metabolism, redox homeostasis, respiration and energy metabolism, and proteolysis. Under severe stress, proteins related to protein metabolism, photosynthesis, RNA metabolism, respiration and energy metabolism, secondary metabolism, defense, and proteolysis were found.

Predominated under moderate stress six photosynthesis-related proteins: Oxygenevolving enhancer protein 2 (spot 9), Mog1/PsbP, alpha/beta/alpha sandwich (spot 42), KK1_025388 (spot 74), Ribulose bisphosphate carboxylase/oxygenase activase, chloroplastic (spot 87) and Putative Rubisco activase (spot 146). Only spot 9 had its value reduced. Paiva (2015) also found this protein in cowpea submitted to two types of stress, in which it had its expression reduced, when compared to the control, a fact similar to that found in this paper.

Stress response proteins were also found: $17.9 \mathrm{kDa}$ class II Heat-Shock Proteins (HSP) (spot 15), CPRD8 protein (spot 93), EXPECTED: protein isomerase-like disulfide (spot 109), and Chaperone DnaK (spot 116), which are related to heat response, oxidoreductase activity, and stress, endoplasmic reticulum stress response, and protein folding. Higher HSP synthesis aids to protect proteins during osmotic stress that occurs after cell dehydration (Zhu et al., 1997). 

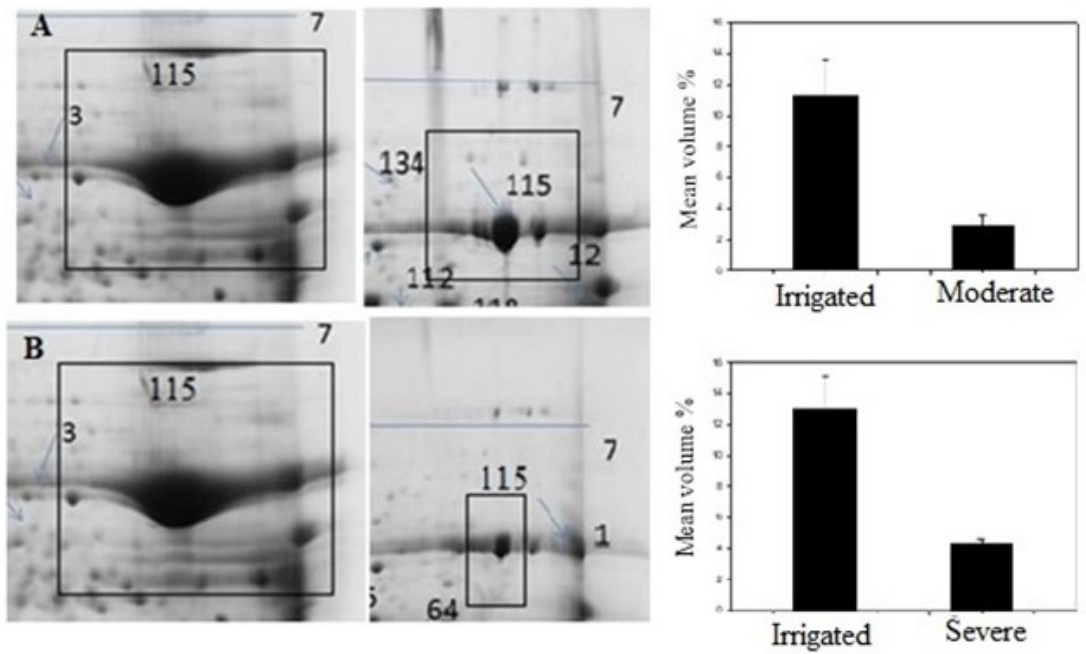

Figure 7. Venn diagram of differentially expressed proteins in leaves of Santo Inácio cowpea under water deficit conditions compared to full irrigation.

The large subunit of Rubisco, partial (chloroplast), appeared three times at the same gel, in spots 26, 100 and 115. An interesting fact, since spots 26 and 100 had their expressions increased while spot 115 had expression reduced (Figure 8).
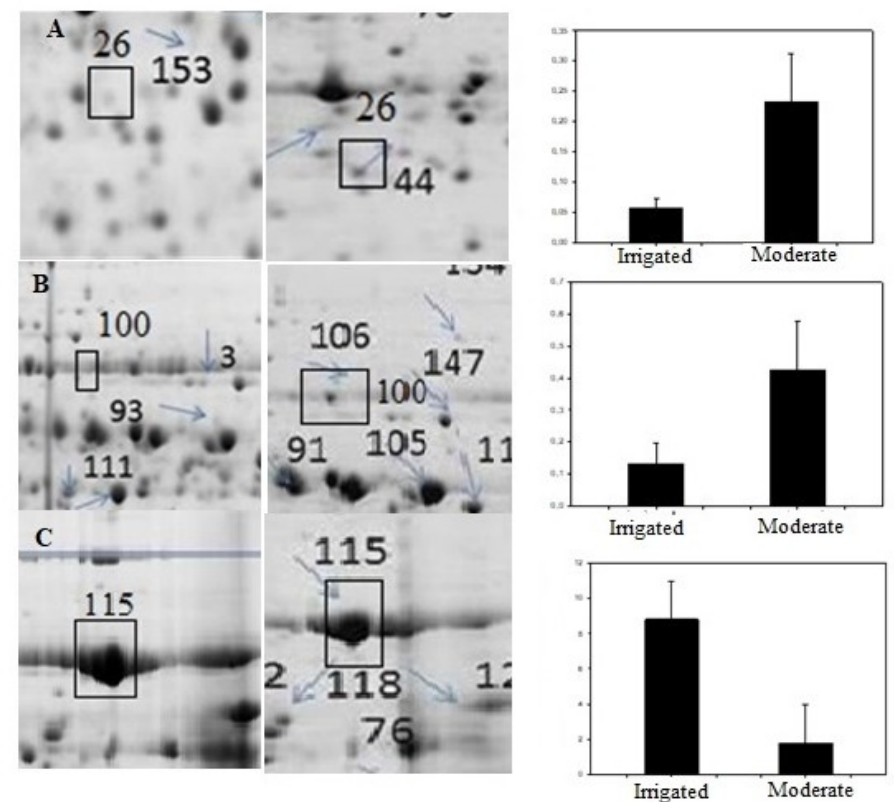

Figure 8. Detail of spots 26, 100 and 115 [large subunit of Ribulose-1,5-bisphosphate carboxylase/oxygenase, partial (chloroplast)] from cowpea leaves. Graphs show values for mean volume percent + standard deviation under each water deficit condition. Figure 8A: spot 26, full irrigation x moderate water stress; Figure 8B: spot 100, full irrigation x moderate water stress; Figure C: spot 115, full irrigation x moderate water stress. 
Under severe water stress, photosynthesis-related proteins also predominated. Small subunit of Rubisco, partial (spot 20), PHAVU_002G024000g (spot 51), ribulose phosphate 3-epimerase, chloroplastic (spot 82), ribulose bisphosphate carboxylase/oxygenase activase, chloroplastic (spot 88), and partial putative rubisco activase (spot 149) were found. Spots 20 and 149 were reduced and spots 82 and 88 were increased. These last two proteins have the function of activating the Rubisco, an important process for photosynthesis. Under high exposure to drought, Rubisco abundance may be reduced, suggesting that $\mathrm{CO}_{2}$ fixation efficiency decreases under water stress (Zadražnik et al., 2013).

Cinnamoyl-CoA reductase 1-like protein (spot 4) related to steroid biosynthesis in secondary metabolism was identified under severe water stress. The mitochondrial serine hydroxymethyltransferase (SHMT, spot 1) were also identified. This protein participates in serine synthesis and in glycine betaine degradation in response to stress. SHMT increased its value compared with the control which may be related to osmotic adjustment in response to stress.

Plants may also respond to stress conditions by affecting protein expression related to respiration and energy metabolism. Pyruvate dehydrogenase E1 component subunit beta (spot 111) had increased expression due to drought stress. It may be because cells need to get extra energy to deal with stress and repair damages. Paiva (2015) also observed increased expression of this protein when cowpea plants were submitted to stress.

\section{DISCUSSION}

Similar alterations in the photosynthetic rate were found by in other species, such as sesame and herbaceous cotton (Souza et al., 1997; Souza et al., 2000; Beltrão et al., 2000), showing that water stress significantly reduces net photosynthesis, but plants can recover the photosynthetic rates after rewatering (Figure 1A). Rivas et al. (2016) also reported that Pingo de Ouro 1,2 recovered the photosynthetic rates when plants were re-irrigated after they were submitted to water stress, confirming the higher photosynthetic performance of this genotype under low water availability. Higher photosynthetic activity is desirable for more drought-tolerant genotypes (Kramer and Boyer, 1995).

Pingo de Ouro 1,2 showed higher gs than Santo Inácio under severe water stress conditions indicating higher stomatal control efficiency, which agreed with Rivas et al. (2016). Such a trait allows higher photosynthetic activity which is desirable for drought tolerance (Kramer and Boyer, 1995).

One of the main mechanisms of the crop to tolerate drought is to avoid tissue dehydration (Nascimento et al., 2011), although this reduces its productive capacity, mainly under prolonged stress. According to Laffay and Louguet (1990), cowpea has both fast stomatal closure and high protoplasmic tolerance, non-opposite adaptive strategies, allowing plant breeders to consider these two characteristics in drought tolerance studies.

Plants accumulated more proline under water stress conditions indicating an osmotic adjustment mechanism in this species (Delauney and Verma, 1993). Many plants accumulate proline mainly under prolonged water stress (Costa et al., 2003), besides as a response to salt-stress (Bohnert et al., 1995). This osmolyte is also produced by plants to stabilize membranes and maintain protein conformation under low water potential caused by the stress (Efeoğlu et al., 2008). 
Differential proteome revealed a modulation in protein expression in both cowpea genotypes. The most expressed proteins in the tolerant genotype were those directly involved in protein metabolism, followed by proteins responsible for photosynthesis, both under full irrigation and water deficit. According to Mesquita et al. (2012), such differences are important mechanisms for tolerance and identification of potential candidate molecules to manipulation for use in genetics in order to select drought-tolerant genotypes. Changes in gene expression and adaptations to tolerance are directly involved with change in protein metabolism, either synthesis or degradation since they play crucial roles in stress tolerance (Kosová et al., 2013).

Glutamine synthetase identified in spot 65 is essential for glutamine biosynthesis and cysteine synthase is the key enzyme in cysteine synthesis, that is necessary for glutathione biosynthesis, considered important for antioxidant metabolism in plants under water stress (Sofo et al., 2010). These proteins along with ribosomal proteins contribute to the synthesis of stress defense proteins and others composts as a strategy of cells to adapt to stress (Zadražnik et al., 2013).

Proteins involved in protein refolding, such as the mitochondrial CPN60-2 chaperonin, were also found. In general, chaperonin plays a crucial role in stress tolerance mechanism by establishing normal protein function conformations (Wang et al., 2004). Another protein involved in protein folding is PHAVU_009G224900g. This protein was abundance in Santo Inácio (sensitive) when compared to Pingo de Ouro 1,2 (tolerant). Zadražnik et al. (2013) also reported that proteins related to protein refolding were more abundant under stress conditions in the sensitive common bean genotype. Sharma et al. (2003) suggest that this effect may be due to the presence of different regulatory pathways in plants.

The protein identified in spot 19 is involved in senescence and drought tolerance processes, according to Feng et al. (2007), and it was more abundant in the sensitive than in the tolerant genotype. Similarly, mitochondrial serine hydroxymethyltransferase (spot 1) was abundant in the sensitive genotype, which may be related to osmotic adjustment in response to stress (Mesquita et al., 2012).

Proteins related to respiration and energy metabolism and their complexes catalyze the global conversion of pyruvate to acetyl-CoA and $\mathrm{CO}_{2}$ (Patel and Roche, 1990; Mooney et al., 2002). These proteins are important for the respiration process in which reduced organic compounds produced in photosynthesis are oxidized and the released energy is used by cells accordingly to plant demand (Wang et al., 2014). In the present study, the tolerant genotype increased the expression of these proteins compared to sensitive. Paiva (2015) also observed increased expression of these proteins in cowpea under saline stress.

Plants continued performing photosynthesis under water stress conditions. However, photosynthetic rates reduced with increasing stress intensity (Figure 1A). According to Inman-bamber (2004), photosynthesis is the first mechanism with great drought sensitivity. However, plants may continue to perform photosynthesis longer than that intended for expanding growth, as the stomata respond more slowly at the onset of water stress than the cell turgor, important for cell elongation that leading to leaf expansion.

Photosynthesis is a key mechanism that provides energy and organic molecules for plant growth and development (Nouri et al., 2015). In this study, many photosynthesisrelated proteins were identified, mainly Rubisco, showing how important this phenomenon is for plant survival. Abreu et al. (2014) reported that Rubisco increased 2.9-fold in the salt- 
sensitive cowpea genotype than in the tolerant under saline stress condition. However, Ali and Komatsu (2006) found decreased Rubisco expression in rice (Oryza sativa L.), while Razavizadeh et al. (2009) verified increased expression in tobacco (Nicotiana tabacum) under saline stress. Moreover, Paiva (2015) observed reduced expression of Rubisco in cowpea under biotic and abiotic stresses compared to control conditions. It shows that this enzyme is subject to both increased and decreased expression under many stress conditions.

Regarding the isoforms, the large subunit of Rubisco, partial (chloroplast), was identified in more than one spot (spots 26, 100 and 115). According to Hajheidari et al. (2005), the same protein present in different spots indicates higher protein degradation rates. Such modifications in Rubisco isoforms in genotypes under stress seem to be posttranslational changes or other changes in gene expression that may play a role in acclimatization to water stress, and not necessarily related to stress tolerance (Mesquita et al., 2012).

Ali and Komatsu (2006) reported low expression of Rubisco isoenzymes in rice under water stress, while Gorantla (2005) observed that a rice cultivar tolerant to water deficit increased expression of the large subunit of Rubisco besides other genes responsive to water deficit. Other studies report the expression of Rubisco fragments due to degradation in response to water stress and jasmonate treatments (Salekdeh et al., 2002). Accumulation of some isoforms of this protein under water deficit seems to be contradictory because when the plant is submitted to water stress, there is a decrease in $\mathrm{CO}_{2}$ input and consequent decrease in photosynthesis. Though, Rubisco shows not only carboxylase activity but also oxygenase activity, by which a process called photorespiration may occur.

Photorespiration protects the photosynthetic apparatus against photoinhibition (Osmond et al., 1997) by maintaining the electron transport chain active thereby preventing the accumulation of electrons and therefore the formation of EROs. Changes in protein accumulation related to Rubisco suggests that accumulation of some isoforms, whether or not resulting from post-translational changes, may induce more tolerance or better acclimation to abiotic stress (Mesquita et al., 2012).

Pingo de Ouro 1,2 cultivar proved its drought tolerance due to some factors like delay in the dehydration process, efficiency in stomatal control, higher photosynthesis rate, and less transpiration. In contrast, Santo Inácio suffered dehydration earlier and closed the stomata under water stress conditions.

By the proteomic analysis was possible to produce differential expression results of the studied system, confirming its use as an important tool in systems biology. Showed significant differences in the abundance in many proteins between the contrasting cowpea genotypes. Most of the proteins identified were related to photosynthesis, the key mechanism for plant survival, which was likely part of a general response to help plants survive in drought conditions.

Drought response-related proteins can be obtained from tolerant genotype and sensitive genotypes. Drought response peptides identified in this study included glutamine synthetase, CPN60-2 chaperonin, mitochondrial, malate dehydrogenase, heat-shock proteins, and rubisco. These can be used as targets for the development of new genotypes and auxiliary molecular markers for cowpea breeding programs to increase water stress tolerance. The differential proteome of cowpea leaves provided an overview of possible 
mechanisms involved in water stress tolerance, launching new perspectives for future studies in specific mechanisms, metabolic pathways, and activity tests of these proteins.

\section{SUPPLEMENTAL MATERIAL}

Supplementary 1. Identification of differentially expressed proteins in cowpea leaves of contrasting genotypes through ESI-Q-TOF MS analysis and NCBI searches. The level of significance considered in the identifications was $\mathrm{P}<0.05$.

\section{ACKNOWLEDGMENTS}

We thank the Coordination for the Improvement of Higher Education Personnel (CAPES, Brazil) the financial support and the Federal University of Ceará for the infrastructure that allowed us to conduct this study.

\section{CONFLICTS OF INTEREST}

The authors declare no conflict of interest.

\section{REFERENCES}

Abreu CEB, Dos Santos GA, De Oliveira ACMM and Gomes-Filho E (2014). Proteomic analysis of salt stress and recovery in leaves of Vigna unguiculata cultivars differing in salt tolerance. Plant Cell. Rep. 33: 1289-1306.

Ali GM and Komatsu S (2006). Proteomic analysis of rice leaf sheath during drought stress. J. Proteome Res. 5: 396403.

Alvarez S, Marsh EL, Schroeder SG and Schachtman DP (2008). Metabolomic and proteomic changes in the xylem sap of maize under drought. Plant Cell. Environ. 3: 325-340.

Bates LS, Waldren RP and Teare ID (1973). Rapid determination of free proline for water-stress studies. Plant Soil. 39: 205-207.

Bastos EA, Ferreira VM, Silva CR and Andrade Júnior AS (2008). Evapotranspiration and cowpea crop coefficient in the Gurguéia Valley, PI. Irriga. 13: 182-190.

Bastos EA, Ramos HMM, Andrade Júnior AD and Cardoso MJ (2012). Physiological parameters and green grain yield of cowpea under water deficit. WRIM. 1: 31-37.

Bohnert HJ, Nelson DE and Jensenay RG (1995). Adaptations to Environmental Stresses. Plant Cell. 7: 1099-1111.

Beltrão NE, De M Souza JG and De Santos JW dos (2000). Consequences of temporary root anoxia on sesame metabolism. Rev. bras. ol fibros. 4: 153-161.

Belko N, Zaman-Allah M, Cisse N and Vadez V (2012). Lower soil moisture threshold for transpiration decline under water deficit correlates with lower canopy conductance and higher transpiration efficiency in drought-tolerant cowpea. Functional Plant Biol. 39: 306-322.

Beltrão NDM, Souza JD, Santos JD and Queiroz UD (2003). Fisiologia da mamoneira, cultivar brs 149 nordestina, na fase inicial de crescimento, submetida a estresse hídrico. Rev. bras. ol fibros. 7: 659-664.

Bradford MM (1976). A rapid and sensitive method for the quantitation of microgram quantities of protein utilizing the principle of protein-dye binding. Anal. Biochem. 7: 248-254.

Costa PH, Silva JV, Bezerra MA, Gomes-Filho E (2003). Growth and organic and inorganic solute contents in NaClstressed cultivars of Vigna unguiculata. Rev bras Bot 26: 289-297.

Delauney AJ and Verma DPS (1993). Proline biosynthesis and osmoregulation in plants. Plant J. 4: 215-223.

Donohue RJ, Roderick ML, Mc Vicar TR and Farquhar GD (2013). Impact of $\mathrm{CO}_{2}$ fertilization on maximum foliage cover across the globe's warm, arid environments. Geophys. Res. Lett. 40: 3031-3035.

Efeoğlu B, Ekmekçi Y and Çiçek N (2008). Physiological responses of three maize cultivars to drought stress and recovery. S. Afr. J. Bot. 75: 34-42.

Feng H, Chen Q, Feng J and Zuo J (2007). Functional characterization of the Arabidopsis eukaryotic translation initiation factor 5A-2 that plays a crucial role in plant growth and development by regulating cell division, cell growth, and cell death. Plant physiol. 144: 1531-1545. 
Goufo P, Moutinho-Pereira JM, Jorge TF and Trindade H (2017). Cowpea (Vigna unguiculata L. Walp.) Metabolomics: Osmoprotection as a Physiological Strategy for Drought Stress Resistance and Improved Yield. Front Plant Science. 8: 586.

Gorantla M, Babu P, Reddy Lachagari V and Reddy AR (2007). Identification of stress-responsive genes in an indica rice (Oryza sativa L.) using ESTs generated from drought-stressed seedlings. J. Exp. Bot. 58: 253-65.

Hajheidari M, Abdollahian-Noghabi M, Askari H and Hosseini Salekdeh G (2005). Proteome analysis of sugar beet leaves under drought stress. Proteomics. 5: 950-960.

Inman-Bamber NG (2004). Sugarcane water stress criteria for irrigation and drying off. Field Crops Res. 89: 107-122.

Kalefetoğlu T and Ekmekçi Y (2005). The effects of drought on plants and tolerance mechanisms. Int. J. Life Sci. 18: 723-740.

Laffay D and Louguet P (1990). Stomatal responses and drought resistance. Bull Soc. Bot. France. 137: 47-60.

Ke Y, Han G and Li (2009). Diffeerential regulation of proteins and phosphoproteins in rice under drought stress. Biochem. Biophys. Res. Commun. 379: 133-138.

Kramer PJ, Boyer JS (1995). Water relations of plants and soils. Academic Press, New York

Kosová K, Prášil IT and Vítámvás P (2013). Protein contribution to plant salinity response and tolerance acquisition. Int. J. Mol. Sci. 14: 6757-6789.

Muchero W, Ehlers JD and Roberts PA (2008). Seedling stage drought-induced phenotypes and drought-responsive genes in diverse cowpea genotypes. Crop. Sci. 48: 541552.

Mesquita RO, Soares E de A, Barros EG de and Loureiro ME (2012). Method optimization for proteomic analysis of soybean leaf: improvements in identification of new and low-abundance proteins. Genet. Mol. Biol. 35: 353-361.

Mooney BP and Miernyk JA and Randall DD (2002). The complex fate of alpha-ketoacids. Annu. Rev. Plant Physiol. Plant Mol. Biol. 53: 357-375.

Nascimento JT, Pedrosa MB and Tavares Sobrinho J (2004). Effect of different levels of available water in the soil on the growth and production of cowpea bean pods and green grains. Hortic. Bras. 22: 174-177.

Nascimento SP, Bastos EA, Araújo ECE and Silva EM (2011). Tolerância ao déficit hídrico e genótipos de feijão-caupi. Rev. Bras. Eng. Agric. Ambient. 15: 853-86.

Neuhoff V, Stamm R and Eibl (1988). Clear background and highly sensitive protein staining with Coomassie Blue dyes in polyacrylamide gels: a systematic analysis. Electrophoresis. 6: 427-448.

Oliveira AD, Fernandes EJ and Rodrigues TJD (2005). Stomatal conductance as an indicator of water stress in bean. Eng. Agric. 25: 86-95.

Osmond B, Badger M, Maxwell K and Leegood R (1997). Too many photons: photorespiration, photoinhibition and photooxidation. Trends plant sci. 2: 119-121.

Paiva ALS (2015). Biochemical response to string bean [Vigna unguiculata L. (WALP)] to saline stress and severe cowpea mosaic virus (CPMV) infection revealed by quantitative free-labeling proteomics. (Masters of Science Thesis). Universidade Federal do Ceara, Fortaleza-Ce. 200p.

Peng Z, Wang M, Li F and Xia GA (2009). A proteomic study of the response to salinity and drought stress in an introgression strain of bread wheat. Mol. Cell Proteomics. 8: 2676-2686.

Nouri MZ, Moumeni A and Komatsu S (2015). Abiotic stresses: insight into gene regulation and protein expression in photosynthetic pathways of plants. Int. J. Mol. Sci. 16: 20392-20416.

Patel MS and Roche TE (1990). Molecular biology and biochemistry of pyruvate dehydrogenase complexes. Faseb. J. 4: 3224-3233.

Razavizadeh R, Ehsanpour AA, Ahsan N and Komatsu S (2009). Proteome analysis of tobacco leaves under salt stress. Peptides. 30: 1651-1659.

Rivas R, Falcão HM, Ribeiro RV and Santos MG (2016). Drought tolerance in cowpea species is driven by less sensitivity of leaf gas exchange to water deficit and rapid recovery of photosynthesis after rehydration. S. Afr. J. Bot. 103: 101-107.

Rodrigues EV, Damasceno-Silva KJ, Rocha MM and Bastos EA (2016). Diallelic analysis to obtain cowpea (Vigna unguiculata L. Walp.) populations tolerant to water deficit. Genet. Mol. Res. 15: gmr7996.

Salekdeh GH, Siopongco J, Wade LJ and Bennett J (2002). Proteomics analysis of rice leaves during drought stress and recovery. Proteomics. 2: 1131-1145.

Santos CF, Lima GPP and Morgado LB (2010). Tolerance and biochemical characterization in cowpea subjected to water stress in pre-flowering. Naturalia. 33: 34-44.

Silva CDS, Santos PAA, Lira JMS and Silva Junior CD (2010). Curso Diário das Trocas Gasosas em Plantas de Feijãocaupi Submetidas à Deficiência Hídrica. . Rev. Caatinga. 23: 7-13.

Sharma S, Sharma SS and Rai VK (2003). Modulation by phenolic compounds of ABA-induced inhibition of mustard (Brassica juncea L. cv. RLM 198) seed germination. Indian J. Exp. Biol. 4: 352-356.

Shevchenko A, Tomas H, Havlis J, Olsen JV, et al. (2006). In-gel digestion for mass spectrometric characterization of proteins and proteomes. Nat. Protoc. 1: 2856-2860.

Sofo A, Cicco N, Paraggio M and Scopa A (2010). Regulation of ascorbate-glutathione cycle in plants under drought stress. In: Ascorbate-glutathione pathway and stress tolerance in plants (Anjum NA, Umar S, Chan M-T eds). Springer, New York.

Genetics and Molecular Research 18 (4): gmr18396

CFUNPEC-RP www.funpecrp.com.br 
Sousa CC, Damasceno-Silva KJ, Bastos EA and Rocha MM (2015). Selection of cowpea progenies with enhanced drought-tolerance traits using principal component analysis. Genet. Mol. Res. 14: 15981-15987.

Souza JG De, Beltrão NE De M and Santos JW dos (1997). Physiology and yield of cotton in flooded soil at the seedling stage. Rev. Bras. ol fibros. 1: 63-71.

Souza JGde, Beltrão NE de M and Santos JW (2000). Fisiologia e produtividade do gergelim em solo com deficiência hídrica. Rev. Bras. ol fibros. 4: 163-168.

Wang W, Vinocur B, Shoseyov O and Altman A (2004). Role of plant heat-shock proteins and molecular chaperones in the abiotic stress response. Trends Plant Sci. 9: 244-52.

Wang X, Vignjevic M, Jiang D and Wollenweber B (2014). Improved tolerance to drought stress after anthesis due to priming before anthesis in wheat (Triticum aestivum L.) var. Vinjett. J. Exp. Bot. 65: 6441-6456.

Zadražnik T, Hollung K, Egge-Jacobsen W and Šuštar-Vozlič J (2013). Differential proteomic analysis of drought stress response in leaves of common bean (Phaseolus vulgaris L.). J. Proteomics. 78: 254-272.

Zhu J, Hasegawa PM and Bressan RA (1997). Molecular aspects of osmotic stress in plants. Crit. Rev. Plant. Sci. 16: 253-277. 